\title{
An increased bone mineral density is an adverse prognostic factor in patients with systemic mastocytosis
}

\author{
Philipp Riffel ${ }^{1}$. Juliana Schwaab ${ }^{2}$. Christopher Lutz ${ }^{1}$. Nicole Naumann ${ }^{2} \cdot$ Georgia Metzgeroth $^{2} \cdot$ Alice Fabarius $^{2}$. \\ Stefan O. Schoenberg ${ }^{1} \cdot$ Wolf-Karsten Hofmann ${ }^{2} \cdot$ Peter Valent $^{3} \cdot$ Andreas Reiter $^{2} \cdot$ Mohamad Jawhar $^{2} \oplus$
}

Received: 15 December 2019 / Accepted: 19 December 2019 / Published online: 24 January 2020

(c) The Author(s) 2020

\begin{abstract}
Purpose Systemic mastocytosis (SM) is characterized by the expansion of clonal mast cells that infiltrate various organ systems. The extent of organ infiltration and subsequent organ damage distinguishes between indolent SM (ISM) defined by a nearly normal life expectancy and advanced SM (AdvSM) defined by poor prognosis. In ISM, measurement of the bone mineral density (BMD) frequently reveals osteoporosis. In contrast, the clinical implication of an increased BMD and osteosclerosis remains unclear.

Methods BMD was evaluated in 61 patients with mastocytosis (ISM, $n=29,48 \%$; AdvSM, $n=32,52 \%$ ). We correlated the prevalence of osteoporosis, increased BMD and osteosclerosis with clinical parameters, disease variant and prognosis. Results Osteoporosis was detected in 11/29 (38\%) patients with ISM but only in 2/32 (6\%) patients with AdvSM $(p=0.004)$. An increased BMD was detected in 1/29 (3\%) patients with ISM and 24/32 (75\%) patients with AdvSM $(p<0.001)$ while osteosclerosis was only detected in AdvSM patients (16/32, 50\%). AdvSM patients with increased BMD had higher levels of bone marrow mast cell infiltration, higher serum tryptase and alkaline phosphatase levels compared to ISM as well as higher number of high-molecular risk mutations $(p<0.05)$. In addition, we found that the prognosis of AdvSM patients with increased BMD is inferior compared to those without increased BMD (median overall survival 3.6 years versus not reached, $p=0.031$ ).
\end{abstract}

Conclusions Osteoporosis is a common feature in ISM but not in AdvSM. An increased BMD is frequently present in AdvSM but not in ISM and is associated with more advanced disease and inferior outcome.

Keywords Advanced systemic mastocytosis · Indolent systemic mastocytosis · Bone mineral density · Osteosclerosis · Osteoporosis · Prognosis

Andreas Reiter and Mohamad Jawhar have contributed equally.

Mohamad Jawhar

mohamad.jawhar@medma.uni-heidelberg.de

1 Institute of Clinical Radiology and Nuclear Medicine, University Hospital Mannheim, Heidelberg University, Mannheim, Germany

2 Department of Hematology and Oncology, University Hospital Mannheim, Heidelberg University, Mannheim, Germany

3 Department of Internal Medicine I, Division of Hematology and Hemostaseology, and Ludwig Boltzmann Institute for Hematology and Oncology, Medical University of Vienna, Vienna, Austria

\section{Introduction}

Systemic mastocytosis (SM) is a rare hematological neoplasm characterized by the expansion of clonal mast cells that infiltrate various organ systems, e.g., bone marrow, liver, spleen, gastrointestinal tract, lymph nodes and skin (Horny et al. 1985; Valent et al. 2001, 2003; Metcalfe 2008; Jawhar et al. 2015). According to the World Health Organization (WHO), the extent of organ infiltration and subsequent organ damage distinguishes between indolent SM (ISM) and advanced SM (AdvSM). AdvSM comprises patients with SM and an associated hematologic neoplasm (SM-AHN), aggressive SM (ASM) and mast cell leukemia (MCL) (Arber et al. 2016).

ISM patients usually present with a low mast cell burden and have a nearly normal life expectancy while AdvSM 
patients usually have a high disease burden, multiple-organ damage and poor prognosis with median overall survival of approximately 3-4 years (Jawhar et al. 2016, 2017a, b, 2019; Valent et al. 2017; Sperr et al. 2019).

Because bone and bone marrow (BM) involvement is a characteristic and frequent feature in SM patients, measurement of the bone mineral density (BMD) plays an important role in the diagnostic workup. According to the literature, the prevalence of osteoporosis ( $T$ score of $\leq-2.5$ standard deviation, SD) in ISM patients ranges between 14 and 66\% (Harvey et al. 1989; Floman and Amir 1991; Brumsen et al. 2002b; Kushnir-Sukhov et al. 2006; Donker et al. 2008; Mathew et al. 2009; Rossini et al. 2011). However, the association between SM subtypes and increased BMD or osteosclerosis is yet unknown.

We, therefore, sought to evaluate the prevalence of osteoporosis, increased BMD and osteosclerosis and their impact on clinical characteristics and prognosis in a large cohort of well-characterized patients with various subtypes of SM.

\section{Materials and methods}

In this retrospective analysis, a total of 61 patients (ISM, $n=29,48 \%$; AdvSM, $n=32,52 \%$ ) were included within our German Registry on Disorders of Eosinophils and Mast Cells.

All patients were scanned on a 16 row CT Scanner (SOMATOM Emotion 16, Siemens Healthcare Sector, Forchheim, Germany). Scans of L1, L2 and L3 were conducted using the following protocol: $120 \mathrm{kV}, 250 \mathrm{mAs}$, and slice thickness $10 \mathrm{~mm}$. Additionally, an in-scan calibration phantom (Siemens OSTEO phantom) was placed beneath the spine during the image acquisition to convert $\mathrm{CT}$ values to BMD. The study design adhered to the tenets of the Declaration of Helsinki and was approved by the institutional review board of the Medical Faculty of Mannheim, Heidelberg University (Heidelberg, Germany). All patients gave written informed consent.

The results were expressed as $T$ score (standard deviation, SD below the mean of young healthy adults) and as $Z$ score (SD below the age- and gender-matched mean reference value). According to established WHO criteria, osteoporosis was defined as a lumbar spine $T$ score of $\leq-2.5 \mathrm{SD}$ (Kanis 1994). Increased BMD and osteosclerosis were defined as $Z$ score $>1 \mathrm{SD}$ and $>2 \mathrm{SD}$, respectively. Because the median age of our cohort was high and following the guidelines of the International Society for Clinical Bone Densitometry (ISCD), we applied the $Z$ score for diagnostic purposes of osteoporosis (Rossini et al. 2011). Severe mastocytosisrelated osteopenia was defined as a lumbar spine $Z$ score of $<-2$ SD (Valent et al. 2007).
All statistical analyses considered clinical and laboratory parameters obtained at time of imaging. Overall survival (OS) was measured from the date of diagnosis to date of death or last visit. OS probabilities were estimated with the Kaplan-Meier method and compared by the log-rank test in univariate analysis. The Wilcoxon-Mann-Whitney $U$ test was used to compare continuous variables and medians of distributions. For categorical variables, two patient groups were compared with the Fisher's exact test. All tests were two sided, retaining $p<0.05$ as statistically significant.

\section{Results}

\section{Disease characteristics}

Patients' characteristics are listed in Table 1. The male:female ratio was $2: 1$. Significant differences between ISM and AdvSM included age (median 42 vs. 70 years, $p<0.0001$ ), hemoglobin (median $14.1 \mathrm{~g} / \mathrm{dL}$ versus $10.9 \mathrm{~g} /$ dL), platelets $\left(263 \times 10^{9} / \mathrm{L}\right.$ vs. $\left.114 \times 10^{9} / \mathrm{L}\right)$, BM mast cell infiltration (median $10 \%$ vs. $30 \%$ ), serum tryptase levels (36 $\mu \mathrm{g} / \mathrm{L}$ vs. $211 \mu \mathrm{g} / \mathrm{L}$ ), alkaline phosphatase (median $70 \mathrm{U} / \mathrm{L}$ vs. $190 \mathrm{U} / \mathrm{L}$ ), frequency of splenomegaly (14\% versus $94 \%$ ) and overall survival (OS, median not reached vs. 3.8 years, $p<0.0001$ ).

\section{Osteoporosis, mastocytosis-related severe osteopenia, and osteosclerosis}

Osteoporosis was detected in 11/29 (38\%) patients with ISM but only in 2/32 (6\%) patients with AdvSM, respectively $(p=0.004)$, while severe mastocytosis-related osteopenia was only diagnosed in ISM patients $(n=3,10 \%)$. A false high BMD due to fractures or vertebroplasty in the lumbar spine was detected in 4/29 (14\%) ISM patients. An increased BMD was diagnosed in 1/29 (3\%) patient with ISM and 24/32 (75\%) patients with AdvSM $(p<0.001)$, respectively, and osteosclerosis only in AdvSM patients (16/32, 50\%, $p<0.0001$, Table 2).

\section{Comparison of ISM patients with and without osteoporosis}

BM mast cell infiltration (median $10 \%$ versus $20 \%$, $p=0.035$ ) and serum tryptase levels (median $31 \mu \mathrm{g} / \mathrm{L}$ versus $58 \mu \mathrm{g} / \mathrm{L}, p=0.047$ ) were significantly lower in ISM patients with osteoporosis $(n=11 ; 38 \%)$ as compared to those without osteoporosis $(n=18,62 \%)$ (Table 3 ).

No significant differences were seen regarding age, gender, blood counts, and OS. Three of 29 (10\%) ISM patients had severe mastocytosis-related osteopenia $(T$ score $<-2)$ (Fig. 1). 
Table 1 Baseline clinical, laboratory, genetic, and outcome characteristics of patients with indolent and advanced systemic mastocytosis

\begin{tabular}{|c|c|c|c|}
\hline Characteristics & ISM $(n=29)$ & $\operatorname{AdvSM}(n=32)$ & $P$ \\
\hline \multicolumn{4}{|l|}{ Age (years) } \\
\hline Median & 42 & 70 & \multirow[t]{2}{*}{$<0.0001$} \\
\hline Range & $28-74$ & $28-82$ & \\
\hline \multicolumn{4}{|l|}{ Sex, $n(\%)$} \\
\hline Men & $12(41)$ & $21(66)$ & NS \\
\hline Women & $17(59)$ & $11(34)$ & NS \\
\hline \multicolumn{4}{|l|}{ Hemoglobin (g/dL) } \\
\hline Median & 14.1 & 10.9 & \multirow[t]{2}{*}{$<0.0001$} \\
\hline Range & $12-15.8$ & $7.5-14,8$ & \\
\hline$<10 \mathrm{~g} / \mathrm{dL}, n(\%)$ & $0(0)$ & $13(41)$ & $<0.0001$ \\
\hline \multicolumn{4}{|l|}{ Platelets $\left(\times 10^{9} / \mathrm{L}\right)$} \\
\hline Median & 263 & 114 & \multirow[t]{2}{*}{$<0.0001$} \\
\hline Range & $124-497$ & $39-577$ & \\
\hline$<100 \times 10^{9} / \mathrm{L}, n(\%)$ & $0(0)$ & $13(41)$ & $<0.0001$ \\
\hline \multicolumn{4}{|c|}{ Mast cell infiltration in BM histology $(\%)$} \\
\hline Median & 10 & 30 & \multirow[t]{2}{*}{0.0003} \\
\hline Range & $5-40$ & $5-95$ & \\
\hline \multicolumn{4}{|l|}{ Serum tryptase $(\mu \mathrm{g} / \mathrm{L})$} \\
\hline Median & 36 & 211 & \multirow[t]{2}{*}{$<0.0001$} \\
\hline Range & $8-106$ & $14-1250$ & \\
\hline \multicolumn{4}{|c|}{ Alkaline phosphatase (U/L) } \\
\hline Median & 70 & 190 & \multirow[t]{2}{*}{$<0.0001$} \\
\hline Range & $40-244$ & $55-756$ & \\
\hline$>\mathrm{UNL}, n(\%)$ & $1(3)$ & $22(69)$ & $<0.0001$ \\
\hline Splenomegaly, $n(\%)$ & $4(14)$ & $30(94)$ & $<0.0001$ \\
\hline KIT D816V positive & $26(90)$ & $31(97)$ & NS \\
\hline \multicolumn{4}{|l|}{ Follow-up (years) } \\
\hline Median & 12.1 & 3.6 & \\
\hline Range & $0.1-29.2$ & $0.1-19.3$ & \\
\hline \multicolumn{4}{|l|}{ Overall survival (years) } \\
\hline Median & NR & 3.8 & \multirow[t]{2}{*}{$<0.0001$} \\
\hline $95 \% \mathrm{CI}$ & - & $2.9-4.7$ & \\
\hline Death, $n(\%)$ & $0(0)$ & $21(66)$ & \\
\hline
\end{tabular}

$A d v S M$ advanced systemic mastocytosis, $B M$ bone marrow, $C I$ confidence interval, ISM indolent systemic mastocytosis, $N R$ not reached, $N S$ non-significant, $U N L$ upper normal limit, WHO World Health Organization

\section{Comparison of AdvSM patients with increased and normal BMD}

In comparison to AdvSM patients with normal BMD $(n=8$, $25 \%)$, AdvSM patients with an increased BMD ( $n=24,75 \%$, Fig. 2) were older (median 77 years vs. 68 years, $p=0.0043$ ) and had lower platelet counts (median $111 \times 10^{9} / \mathrm{L}$ vs. $\left.238 \times 10^{9} / \mathrm{L}, p=0.041\right)$. AdvSM patients with an increased BMD presented with significantly higher levels of BM mast cell infiltration (median $50 \%$ vs. $10 \%, p=0.002$ ) (Table 4 , Fig. 3), significantly higher serum tryptase levels (median
Table 2 Frequency of osteoporosis, mastocytosis-related osteoporosis, increased bone mineral density, and osteosclerosis in patients with indolent and advanced systemic mastocytosis SM

\begin{tabular}{lcll}
\hline Characteristics & ISM $(n=29)$ & $\operatorname{AdvSM}(n=32)$ & $P$ \\
\hline Osteoporosis $^{\mathrm{a}}, n(\%)$ & $11(38)$ & $2(6)$ & 0.004 \\
$\begin{array}{l}\text { Mastocytosis-related } \\
\quad 3(10)\end{array}$ & $0(0)$ & 0.1 \\
$\quad$ ssteoporosis $^{\mathrm{b}}, n(\%)$ & & & \\
Increased BMD $^{\mathrm{c}}, n(\%)$ & $1(3)$ & $24(75)$ & $<0.001$ \\
Osteosclerosis $^{\mathrm{d}}, n(\%)$ & $0(0)$ & $16(50)$ & $<0.0001$ \\
\hline
\end{tabular}

$A d v S M$ advanced systemic mastocytosis, $B M D$ bone mineral density, ISM indolent systemic mastocytosis

${ }^{\mathrm{a}} T$ score of $\leq-2.5$ standard deviation (SD)

${ }^{\mathrm{b}} Z$ score $<-2 \mathrm{SD}$

${ }^{\mathrm{c}} Z$ score $>1 \mathrm{SD}$

${ }^{\mathrm{d}} Z$ score $>2 \mathrm{SD}$

Table 3 Clinical and laboratory characteristics of patients with indolent systemic mastocytosis with and without osteoporosis

\begin{tabular}{llll}
\hline Characteristics & $\begin{array}{l}\text { No osteoporosis } \\
(n=18)\end{array}$ & $\begin{array}{l}\text { Osteoporosis } \\
(n=11)\end{array}$ & $P$ \\
\hline $\begin{array}{l}\text { Age (years) } \\
\text { Median }\end{array}$ & 41 & 44 & NS \\
$\quad$ Range & $28-66$ & $32-74$ & \\
Sex, $n(\%)$ & & NS \\
$\quad$ Men & $8(44)$ & $5(45)$ & NS \\
$\quad$ Women & $10(56)$ & $6(55)$ & \\
Mast cell infiltration in BM histology $(\%)$ & & 0.035 \\
$\quad \begin{array}{l}\text { Median } \\
\text { Range }\end{array}$ & 20 & 10 & \\
Serum tryptase $(\mu \mathrm{g} / \mathrm{L})$ & $5-40$ & $5-30$ & 0.047 \\
$\quad$ Median & 58 & & \\
Range & $8-106$ & $10-83$ & \\
\hline
\end{tabular}

$B M$ bone marrow

$262 \mu \mathrm{g} / \mathrm{L}$ versus $62 \mu \mathrm{g} / \mathrm{L}, p=0.003)$, significantly higher alkaline phosphatase levels (median $238 \mathrm{U} / \mathrm{L}$ versus $74 \mathrm{U} / \mathrm{L}$, $p<0.0001$ ), a higher KIT D816V allele burden (median 30\% versus $4.3 \%, p=0.046$ ), higher number of mutations in the high-molecular risk panel (SRSF2, ASXL1, RUNX1, S/A/R gene panel), and an inferior survival (median 3.6 years versus not reached, $p=0.031$ ) (Fig. 4). No significant differences regarding clinical/histological/laboratory and genetic characteristics were seen between patients with an increased BMD and those which were even classified as osteosclerosis (data not shown). 


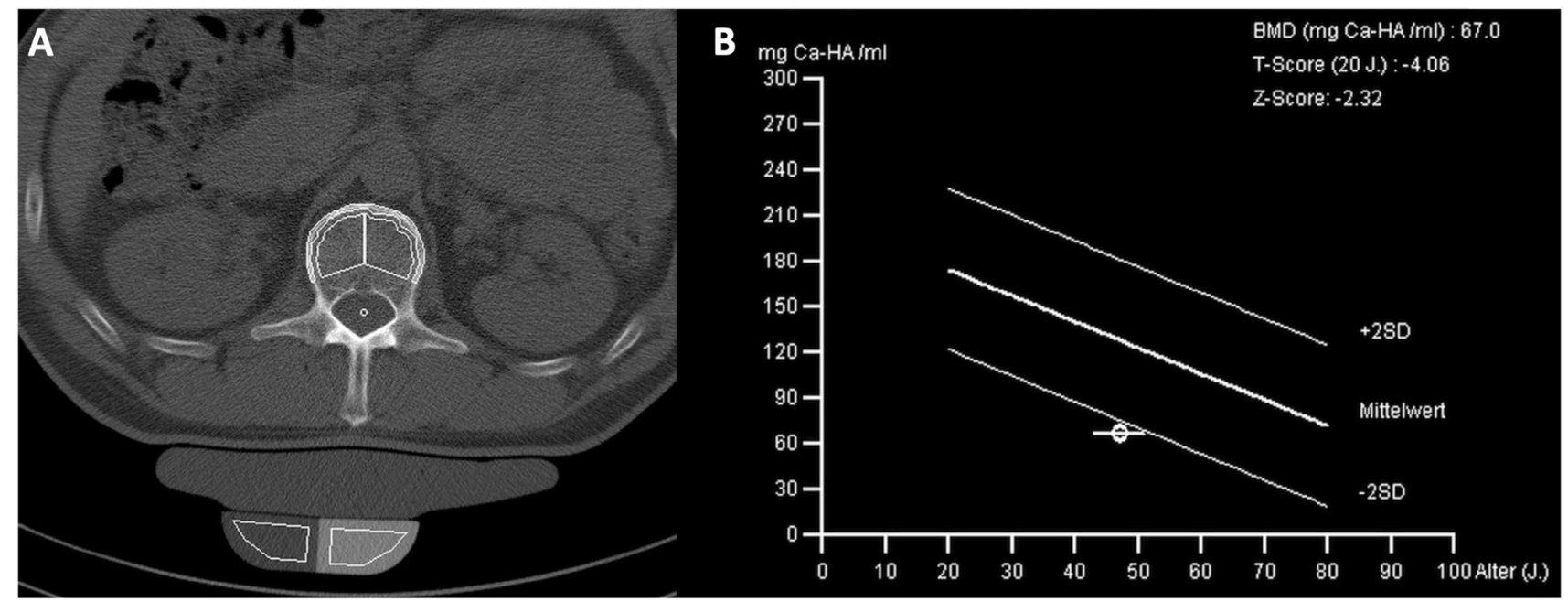

Fig. 1 a Computed tomography scan of L1 and $\mathbf{b}$ bone mineral density (BMD) in a 56-year-old male patient with indolent systemic mastocytosis (ISM) and severe osteoporosis according to the traditional

\section{Discussion}

So far, only little is known about differences in the prevalence of decreased or increased BMD in the various SM subtypes finally leading to the diagnosis of osteoporosis or osteosclerosis. In addition, the impact of an altered BMD on complications and outcome remains largely unknown (Huang et al. 1987; Johansson et al. 1996; Barete et al. 2010; Manara et al. 2010; Rossini et al. 2011). We, therefore, evaluated $T$ and $Z$ scores in a larger number of patients with ISM and AdvSM.

Osteoporosis is a typical feature of ISM and has been attributed to the local release of mediators such as histamine, heparin or mast cell-derived proteases (Harvey et al. 1989; Floman and Amir 1991; Brumsen et al. 2002a; KushnirSukhov et al. 2006; Donker et al. 2008; Mathew et al. 2009). In line with previous reports (Harvey et al. 1989; Floman and Amir 1991; Brumsen et al. 2002b; Kushnir-Sukhov et al. 2006; Donker et al. 2008; Mathew et al. 2009; Rossini et al. 2011), osteoporosis was detected in $38 \%$ of our patients with ISM but in only $6 \%$ of the cases with AdvSM. According to Rossini et al., a $Z$ score $<2.0$ indicating mastocytosis-related severe osteopenia was identified in $10 \%$ of our ISM patients. However, another $14 \%$ of the ISM patients examined showed false high BMD values due to fractures and/or vertebroplasty in the lumbar spine.

ISM patients with osteoporosis had a significantly lower median mast cell infiltration in the bone marrow and a lower median serum tryptase level as compared to ISM patients without osteoporosis (Johansson et al. 1996; Kushnir-Sukhov et al. 2006; Rossini et al. 2014). A significant positive correlation was observed between serum tryptase levels
WHO criteria ( $T$ score: -4.06 ). Also, a mastocytosis-related low $\mathrm{BMD}$ is present with a $Z$ score of -2.32

and $T$ score BMD in the subgroup of ISM. Johansson et al. assumed that mast cell mediators stimulating osteoclasts are dominant in patients with a moderate increase of mast cells, while the osteoblast-stimulating effect of histamine prevails in patients with high histamine metabolite excretion (Johansson et al. 1996).

In contrast to ISM, the vast majority of our AdvSM patients had no osteoporosis but an increased BMD or even osteosclerosis. AdvSM patients with increased BMD/osteosclerosis had a more aggressive phenotype, e.g., a higher mast cell burden in the bone marrow compared to our ISM patients, and the same was found to hold true for serum tryptase, KIT D816V EAB and alkaline phosphatase. In addition, we found that patients with increased BMD have an inferior outcome as compared to AdvSM patients with normal BMD. Almost all AdvSM patients with a normal BMD had an SM-AHN with a dominating AHN and a relatively low mast cell burden.

Osteosclerosis is observed in a number of hematologic neoplasms and is recognized as an adverse prognostic (Rollison et al. 2008) feature in myeloproliferative neoplasms (MPN) such as primary myelofibrosis, secondary myelofibrosis, polycythemia vera and essential thrombocythemia. Two previous studies with six SM patients have shown that osteosclerosis was associated with more advanced SM subtypes (Kushnir-Sukhov et al. 2006; Barete et al. 2010). In a recent MRI-based study, a diffuse sclerotic bone marrow pattern of the spine was associated with a significantly higher MC burden, organ dysfunction and inferior survival (Riffel et al. 2019).

The pathophysiology of AdvSM-related increased $\mathrm{BMD} /$ osteosclerosis is poorly understood. Mast 


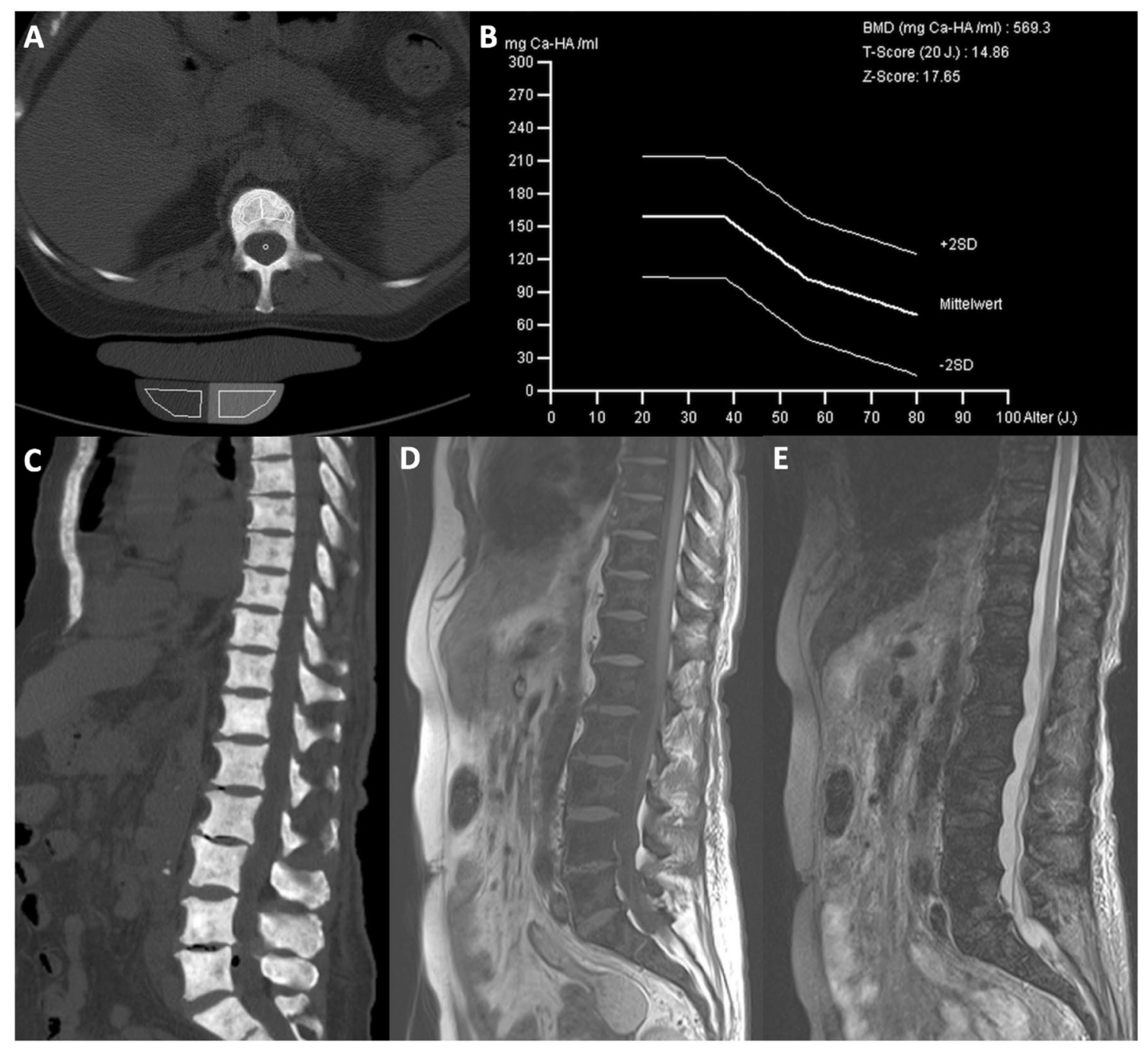

Fig. 2 a Computed tomography (CT) scan of L1 and b bone mineral density (BMD) in a 77-year-old male patient with advanced systemic mastocytosis (AdvSM). Severe osteosclerosis is reflected in the $Z$ score of 17.65 and in the corresponding CT scan of the spine (c).
Also, magnetic resonance imaging (MRI) images of the spine showed diffuse osteosclerosis with a very low signal both in T1-weighted (d) and turbo inversion recovery magnitude (TIRM)-sequences (e) cell-derived mediators and cytokines may exert a direct stimulatory effect on osteoblast recruitment, proliferation, and activity, while tryptase may increase osteoprotegerin, reducing osteoclast activity and favouring osteosclerosis rather than osteoporosis (Johansson et al. 1996; Chiappetta and Gruber 2006; Gregson et al. 2013).
In conclusion, (1) osteoporosis is a common feature in ISM but not in AdvSM, (2) an increased BMD and osteosclerosis are frequently present in AdvSM but not in ISM, (3) in AdvSM, an increased BMD/osteosclerosis is associated with a more aggressive phenotype, high-risk molecular aberrations, and inferior survival. 
Table 4 Clinical, laboratory, genetic, and outcome characteristics of patients with advanced SM with normal and increased bone mineral density

\begin{tabular}{|c|c|c|c|}
\hline Characteristics & $\begin{array}{l}\text { Increased } \\
\text { BMD } \\
(n=24)\end{array}$ & Normal BMD $(n=8)$ & $P$ \\
\hline \multicolumn{4}{|l|}{ Age (years) } \\
\hline Median & 77 & 68 & 0.043 \\
\hline Range & $53-81$ & $28-82$ & \\
\hline \multicolumn{4}{|l|}{ Sex, $n(\%)$} \\
\hline Men & $15(63)$ & $6(75)$ & NS \\
\hline Women & $9(37)$ & $2(25)$ & NS \\
\hline \multicolumn{4}{|l|}{ WHO classification } \\
\hline ASM, $n(\%)$ & $3(12)$ & $1(12)$ & NS \\
\hline SM-AHN, $n(\%)$ & $17(71)$ & $7(88)$ & NS \\
\hline $\mathrm{MCL} \pm \mathrm{AHN}, n(\%)$ & $4(17)$ & 0 & NS \\
\hline \multicolumn{4}{|l|}{ Hemoglobin (g/dL) } \\
\hline Median & 10.5 & 12.9 & NS \\
\hline Range & $7.9-14.2$ & $7.5-14.8$ & \\
\hline$<10 \mathrm{~g} / \mathrm{dL}, n(\%)$ & $11(46)$ & $2(25)$ & NS \\
\hline \multicolumn{4}{|l|}{ Platelets $\left(\times 10^{9} / \mathrm{L}\right)$} \\
\hline Median & 111 & 238 & 0.041 \\
\hline Range & 39-312 & $45-577$ & \\
\hline$<100 \times 10^{9} / \mathrm{L}, n(\%)$ & $11(46)$ & $2(25)$ & NS \\
\hline \multicolumn{4}{|c|}{ Mast cell infiltration in BM histology (\%) } \\
\hline Median & 50 & 10 & 0.002 \\
\hline Range & $5-95$ & $5-30$ & \\
\hline \multicolumn{4}{|l|}{ Serum tryptase $(\mu \mathrm{g} / \mathrm{L})$} \\
\hline Median & 262 & 62 & 0.003 \\
\hline Range & $30-1250$ & $14-230$ & \\
\hline \multicolumn{4}{|c|}{ Alkaline phosphatase ${ }^{\mathrm{a}}(\mathrm{U} / \mathrm{L})$} \\
\hline Median & 238 & 74 & $<0.0001$ \\
\hline Range & $76-756$ & $55-173$ & \\
\hline$>\mathrm{UNL}, n(\%)$ & $21(88)$ & $1(13)$ & $<0.001$ \\
\hline \multicolumn{4}{|l|}{ KIT D816V EAB (\%) } \\
\hline Median & 30 & 4.3 & 0.046 \\
\hline Range & $1-50$ & $1-64$ & \\
\hline \multicolumn{4}{|l|}{ S/A/R mutation(s) } \\
\hline 1 mutation, $n(\%)$ & $19(75)$ & $4(50)$ & NS \\
\hline$\geq 2$ mutations, $n(\%)$ & $10(42)$ & 0 & 0.035 \\
\hline \multicolumn{4}{|l|}{ Follow-up (years) } \\
\hline Median & 3.6 & 5.5 & NS \\
\hline Range & $0.1-14.5$ & $0.8-19.3$ & \\
\hline \multicolumn{4}{|l|}{ Overall survival (years) } \\
\hline Median & 3.6 & NR & 0.031 \\
\hline $95 \% \mathrm{CI}$ & $2.1-5.1$ & & \\
\hline Death, $n(\%)$ & $19(79)$ & $2(25)$ & \\
\hline
\end{tabular}

$A d v S M$ advanced systemic mastocytosis; $A H N$ associated hematologic neoplasm; $A S M$ aggressive SM; $B M$ bone marrow; $B M D$ bone mineral density; $C I$ confidence interval; $E A B$ expressed allele burden; $M C L$ mast cell leukemia; $N R$ not reached; $N S$ non-significant; $S / A / R$ one or more gene mutations in $S R S F 2, A S X L 1, R U N X 1 ; U N L$ upper normal limit

${ }^{\text {a }}$ The comparison between normal BMD and increased BMD regarding median surivval

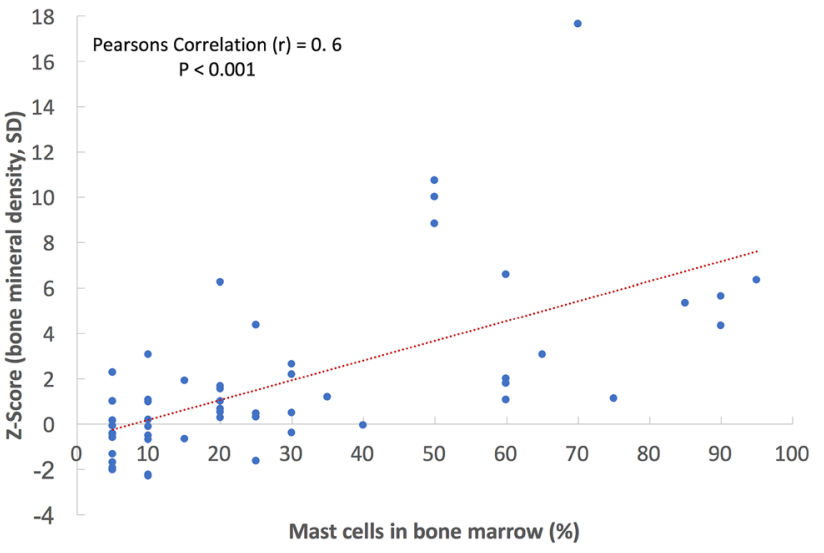

Fig. 3 Correlation between bone mineral density and mast cell infiltration in bone marrow histology in patients with systemic mastocytosis
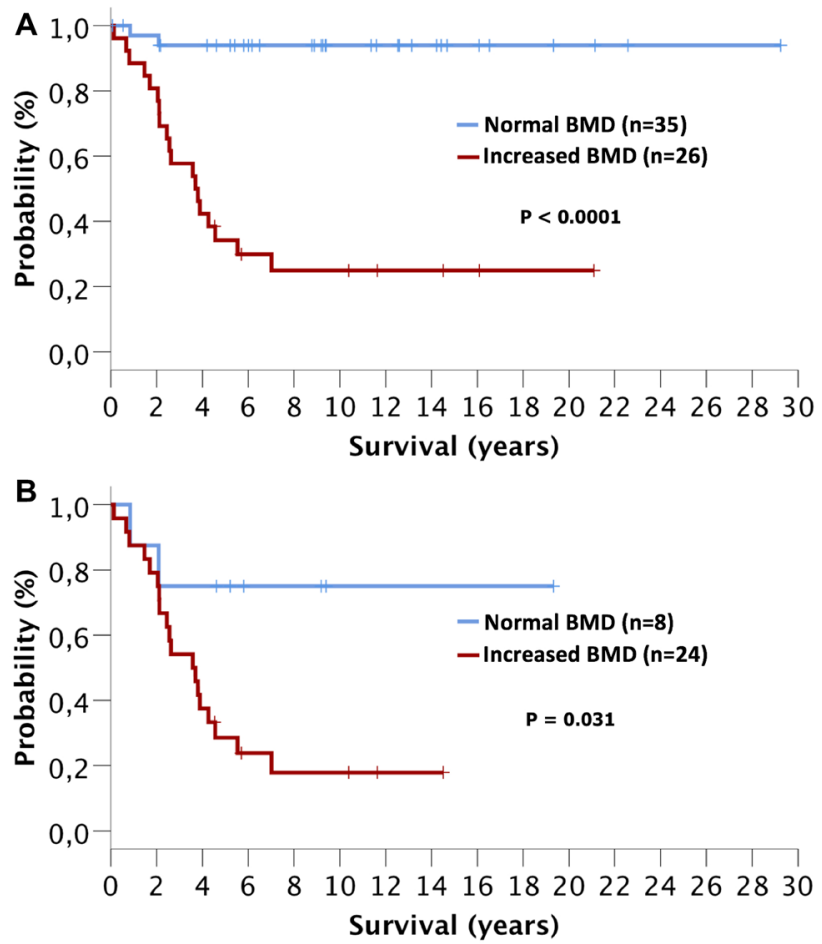

Fig. 4 Overall survival of systemic mastocytosis (SM) patients with normal or increased bone mineral density (BMD). a Patients with indolent SM and advanced SM (AdvSM) and b patients with AdvSM

Acknowledgements Open Access funding provided by Projekt DEAL. This research did not receive any specific grant from funding agencies in the public, commercial, or not-for-profit sectors.

Open Access This article is licensed under a Creative Commons Attribution 4.0 International License, which permits use, sharing, adaptation, distribution and reproduction in any medium or format, as long as you give appropriate credit to the original author(s) and the source, provide a link to the Creative Commons licence, and indicate if changes 
were made. The images or other third party material in this article are included in the article's Creative Commons licence, unless indicated otherwise in a credit line to the material. If material is not included in the article's Creative Commons licence and your intended use is not permitted by statutory regulation or exceeds the permitted use, you will need to obtain permission directly from the copyright holder. To view a copy of this licence, visit http://creativecommons.org/licenses/by/4.0/.

\section{References}

Arber DA et al (2016) The 2016 revision to the World Health Organization classification of myeloid neoplasms and acute leukemia. Blood 20:2391-2405

Barete $\mathrm{S}$ et al (2010) Systemic mastocytosis and bone involvement in a cohort of 75 patients. Ann Rheum Dis 10:1838-1841

Brumsen C et al (2002a) Osteoporosis and bone marrow mastocytosis: dissociation of skeletal responses and mast cell activity during long-term bisphosphonate therapy. J Bone Miner Res 4:567-569

Brumsen C et al (2002b) A potential role for the mast cell in the pathogenesis of idiopathic osteoporosis in men. Bone 5:556-561

Chiappetta N, Gruber B (2006) The role of mast cells in osteoporosis. Semin Arthritis Rheum 1:32-36

Donker ML et al (2008) Two patients with osteoporosis: initial presentation of systemic mastocytosis. J Bone Miner Metab 2:199-202

Floman Y, Amir G (1991) Systemic mastocytosis presenting with severe spinal osteopenia and multiple compression fractures. J Spinal Disord 3:369-373

Gregson CL et al (2013) Friend or foe: high bone mineral density on routine bone density scanning, a review of causes and management. Rheumatology (Oxford) 6:968-985

Harvey JA et al (1989) Osteoporosis associated with mastocytosis confined to bone: report of two cases. Bone 4:237-241

Horny HP et al (1985) Bone marrow findings in systemic mastocytosis. Hum Pathol 8:808-814

Huang TY et al (1987) Radiological features of systemic mast-cell disease. Br J Radiol 716:765-770

Jawhar M et al (2015) Molecular profiling of myeloid progenitor cells in multi-mutated advanced systemic mastocytosis identifies KIT D816V as a distinct and late event. Leukemia 5:1115-1122

Jawhar M et al (2016) Additional mutations in SRSF2, ASXL1 and/ or RUNX1 identify a high-risk group of patients with KIT D816V(+) advanced systemic mastocytosis. Leukemia 1:136-143

Jawhar M et al (2017a) The clinical and molecular diversity of mast cell leukemia with or without associated hematologic neoplasm. Haematologica 6:1035-1043
Jawhar M et al (2017b) Response and progression on midostaurin in advanced systemic mastocytosis: KIT D816V and other molecular markers. Blood 2:137-145

Jawhar M et al (2019) MARS: mutation-adjusted risk score for advanced systemic mastocytosis. J Clin Oncol 31:2846-2856

Johansson C et al (1996) Bone density, bone markers and bone radiological features in mastocytosis. Age Ageing 1:1-7 (Johansson, 1996 \#19)

Kanis JA (1994) Assessment of fracture risk and its application to screening for postmenopausal osteoporosis: synopsis of a WHO report. WHO Study Group. Osteoporos Int 6:368-381

Kushnir-Sukhov NM et al (2006) Elevated tryptase levels are associated with greater bone density in a cohort of patients with mastocytosis. Int Arch Allergy Immunol 3:265-270

Manara $\mathrm{M}$ et al (2010) Osteoporosis with vertebral fractures in young males, due to bone marrow mastocytosis: a report of two cases. Clin Exp Rheumatol 1:97-100

Mathew R et al (2009) Systemic mastocytosis presenting as osteoporosis-a case report. Clin Rheumatol 7:865-866

Metcalfe DD (2008) Mast cells and mastocytosis. Blood 4:946-956

Riffel P et al (2019) Magnetic resonance imaging reveals distinct bone marrow patterns in indolent and advanced systemic mastocytosis. Ann Hematol 98:2693-2701

Rollison DE et al (2008) Epidemiology of myelodysplastic syndromes and chronic myeloproliferative disorders in the United States, 2001-2004, using data from the NAACCR and SEER programs. Blood 1:45-52

Rossini M et al (2011) Bone mineral density, bone turnover markers and fractures in patients with indolent systemic mastocytosis. Bone 4:880-885

Rossini M et al (2014) Bone involvement and osteoporosis in mastocytosis. Immunol Allergy Clin N Am 2:383-396

Sperr WR et al (2019) International prognostic scoring system for mastocytosis (IPSM): a retrospective cohort study. Lancet Haematol 6:e638-e649

Valent $P$ et al (2001) Diagnostic criteria and classification of mastocytosis: a consensus proposal. Leuk Res 7:603-625

Valent $\mathrm{P}$ et al (2003) Diagnosis and treatment of systemic mastocytosis: state of the art. Br J Haematol 5:695-717

Valent P et al (2007) Standards and standardization in mastocytosis: consensus statements on diagnostics, treatment recommendations and response criteria. Eur J Clin Invest 6:435-453

Valent P et al (2017) Mastocytosis: 2016 updated WHO classification and novel emerging treatment concepts. Blood 11:1420-1427

Publisher's Note Springer Nature remains neutral with regard to jurisdictional claims in published maps and institutional affiliations. 